\title{
Clinical and sonographic evaluation of the diaphragm after plication in adults with unilateral eventration: a retrospective study
}

Mohamed Abdel-Bary ${ }^{1 *}$ (D) Alaa Rashad ${ }^{2}$, Hamed Elgendy $^{3}$, Mohammed Zaki $^{4}$, Mahmoud Youssef Abdelhamid ${ }^{5}$, Morris Beshay ${ }^{6}$ and Khaled Mohamed Abdelaal ${ }^{7}$

\begin{abstract}
Background: We aim to assess the role of diaphragm ultrasonography in evaluating the outcome of surgical diaphragmatic plication in adults with symptomatic unilateral diaphragmatic eventration.

Results: Forty patients with symptomatic unilateral diaphragmatic eventration underwent surgical diaphragmatic plication between 2015 and 2020. The etiology was idiopathic in 34 (85\%) cases, and 37 (92.5\%) of them were suffering from dyspnea. Diaphragm ultrasonography showed no diaphragmatic movement on the affected side in 10 (25\%) patients and a paradoxical movement in 30 (75\%) patients. Surgical diaphragmatic plication was done successfully in all cases. Postoperative complications were reported in $3(7.5 \%)$ cases, with no mortality. There was a highly significant improvement in dyspnea at 1 week and 6 months follow-up. CXR showed a highly significant decrease in the mean height of eventration at 1 week $3.7 \pm 1.2 \mathrm{~cm}(P<0.001)$, and 6 months $2.6 \pm 0.9 \mathrm{~cm}(P<0.001)$, compared to preoperative values $(10.1 \pm 2.8 \mathrm{~cm})$. diaphragm ultrasonography showed normal motility of the plicated cupola in all cases, and there was a highly significant decrease in the mean height of eventration at 1 week $(3.1 \pm 1.1 \mathrm{~cm}, P<0.001)$, and 6 months $(2.3 \pm 0.5 \mathrm{~cm}, P<0.001)$ compared to preoperative values $(10.3 \pm 2.2 \mathrm{~cm})$. There was a highly significant increase in the diaphragm thickness at 1 week $(2.7 \pm 0.3 \mathrm{~mm}, P<0.001)$, and 6 months $(2.9 \pm 0.2 \mathrm{~mm}, P<0.001)$, compared to the preoperative value. There was a highly significant improvement in the degree of excursion 1 week ( $25 \pm 4.3 \mathrm{~mm}, P<0.001)$, and 6 months $(28 \pm 5.2 \mathrm{~mm}, P<0.001)$, compared to the preoperative value $(15 \pm 6.2 \mathrm{~mm})$. No fluid collection or surroundings organ injuries were detected. The mean FVC and FEV1 showed a highly significant improvement at 1 week $(66.7 \pm 6 \%, 78.2 \pm 9.8 \%)$, and 6 months $(68.8 \pm 5.7 \%, 80.4 \pm 10.3 \%)$, compared to the preoperative value (58.8 $\pm 8 \%$ and $70.9 \pm 10.3 \%)$.
\end{abstract}

Conclusions: Surgical diaphragmatic plication is an effective and safe procedure that can be performed to treat symptomatic adults with unilateral diaphragmatic eventration. Diaphragm ultrasonography can be used as a simple bedside test to evaluate unilateral diaphragmatic eventration cases and their postoperative follow-up.

Keywords: Diaphragm plication, Diaphragmatic eventration, Diaphragm ultrasonography

${ }^{*}$ Correspondence: Dr_abdelbary@med.svu.edu.eg

1 Department of Cardiothoracic Surgery, Qena Faculty of Medicine, South

Valley University, Safaga Road, Qena 83523, Egypt

Full list of author information is available at the end of the article

\section{Background}

Unilateral diaphragmatic eventration (UDE) is defined as a fixed raised hemidiaphragm without defects in its continuity. This occurs due to congenital or acquired phrenic nerve dysfunction [1]. Dyspnea and orthopnea 
are the most frequent complaints [2]. Few patients were discovered accidentally. No treatment is required for asymptomatic cases. However, symptomatic cases should be managed by surgical plication [3, 4]. Iatrogenic UDE was observed for up to 2 years because it may improve with time. However, this observation should be limited to 6 months before surgery in severe cases $[5,6]$. Surgical diaphragmatic plication (SDP) has become the rationale in the management of UDE $[7,8]$. In this procedure, the eventrated paralyzed cupola is multi-folded on itself and fixed with nonabsorbable sutures. This alleviates shortness of breath by limitation of diaphragmatic elevation during inspiration [9].

Sometimes, it is difficult to diagnose UDE since the symptoms are complex and no test has a strong diagnostic value [10]. The used radiolo/gical investigations are sometimes insensitive, painful, or invasive. Recently, diaphragm ultrasonography (DUS) has evolved as a simple, cheap, non-invasive, promptly accessible, reproducible, and bedside examination for appraisal of the dynamic movement and function of the diaphragm $[11,12]$. Moreover, DUS has no risk of ionizing radiation and allows better visualization of supra and infra diaphragmatic structures [13]. Additionally, it overcomes many of the drawbacks of other diagnostic techniques for the assessment of the diaphragm. Its value for the anticipation of weaning outcomes in critically ill, mechanically ventilated patients was reported [14].

Up to date, no large reports on the use of sonography for the evaluation of UDE were done [15]. Besides, there are no studies about the use of sonography for the postoperative assessment of the diaphragm after plication. Especially that there are some outcomes that cannot be assessed by the other radiological investigations such as the dynamic movement and the excursion of the diaphragm. Also, it can assess the integrity, thickness, and smoothness of the diaphragm. Moreover, the complications, the surrounding organs' injuries, or fluid collection can be evaluated. Therefore, we aimed to assess the role of DUS in the evaluation of the outcome of SDP in adults with symptomatic UDE; in association with clinical, radiological, and respiratory function test (RFT) evaluation.

\section{Methods}

\section{Study design}

A retrospective study included symptomatic UDE patients who underwent SDP presented during a period from January 2015 to January 2020. The study conformed to the ethical standards of the Helsinki Declaration and approval was obtained from the local institutional ethics committee. The requirement for informed consent was waived. The outcomes assessed were clinical, radiological, and RFT evaluation.

\section{Subjects}

The data of all patients were collected from patients' records. The indication for SDP was symptomatic UDE in adults after radiological confirmation. Children, morbid obesity, certain neuromuscular disorders, previous thoracic surgical intervention on the affected side, or recurrent eventration cases were excluded from the study. Computed tomography scans were required only to rule out other causes of phrenic nerve involvement or a subphrenic lesion causing hemidiaphragm elevation. All patients underwent clinical dyspnea evaluation according to MRC score, chest X-ray (CXR), DUS, and RFT. The patients were evaluated in 1 week and 6 months postoperatively.

\section{Chest X-ray}

The height of the eventration was determined and compared with the cupola of the healthy side by CXR, preoperatively. These values were calculated and compared with the degree of CXR changes at 1 week and 6 months postoperatively.

\section{Diaphragm ultrasonography}

All cases were examined in the supine and sitting positions. DUS was done using a general imaging ultrasound machine (Philips Clearvue 350). An acoustic gel was placed on the patient's skin at a low frequency of $3.5 \mathrm{C}$ (bandwidth $2-5 \mathrm{MHz}$ ) and a high frequency $(8-12)$ transducer was used to provide better resolution of deep and superficial structures. The M-mode was used for the assessment of the diaphragmatic movement quantitatively by using two parameters: direction of motion and amplitude of excursion. The diaphragmatic movement is considered normal if the diaphragm moves toward the transducer during inspiration, with an excursion of greater than $4 \mathrm{~mm}$ and a difference in excursion between the cupolae of less than 50\%. Two-dimensional B-mode US was used to measure diaphragm thickness at the zone of apposition during inspiration or expiration using the intercostals approach [16]. The diaphragm was visualized by placing the sonography probe in the ninth intercostal space perpendicular to the 9th and 10th ribs, between the right or left anterior and the midaxillary lines. A fixed point on the bony structure was the upper border of the 1st rib, while the patient was setting. The height of the eventration was determined and compared with the healthy cupola. We put the probe in the subcostal region near the mid-clavicular line to assess diaphragmatic excursion and moved until the posterior portion of the diaphragm was better visible. The M-mode was then utilized to display the diaphragmatic excursion along a specified line perpendicular to the diaphragm during tidal 
breathing. From the baseline until the moment of maximum height of inspiration, the amplitude of diaphragmatic excursion was quantified on the vertical axis of the tracing. This technique was performed three times, with the average being taken [17]. DUS was done within the first week postoperative for assessment of the dynamic movements and excursion of the diaphragm. Also, it was used for the assessment of the integrity, thickness, and smoothness of the diaphragm. Even the surrounding organs' injuries or fluid collection were evaluated. The preoperative values of the DUS were compared with the postoperative values after 1 week and 6 months.

\section{Respiratory function tests}

Spirometry with reversibility test was done by microlab portable electronic spirometer (2008; Micromedical limited, Rochester, UK). They were done for the assessment of forced expiratory volume 1 (FEV1) and forced vital capacity (FVC). The preoperative values of the RFT were compared with the values 1 week and 6 months postoperatively.

\section{Surgical procedures}

The plication was done either via a posterolateral thoracotomy in the eighth intercostal space or using three points VATS procedure on the affected side according to the degree of the diaphragmatic eversion. The diaphragm with the abdominal contents was pushed caudally until the normal position of the cupola was achieved. At this position, a fold of approximately $5 \mathrm{~cm}$ was made using traction forceps of the reluctant diaphragm. Polypropylene sutures were used to perform plication of the diaphragm by making a fold on itself without tissue resection. Plication was performed using interrupted polypropylene U-stitches; usually, it started from the posterior part to the anterior part of the diaphragm. This is followed by merging and fixing these folds with continuous polypropylene sutures. The diaphragm now becomes tough and firm and returned to its normal position. Caution is to be taken to avoid overcorrection of the diaphragm, as it might have much pressure on the other side of the diaphragm, or it may lead to postoperative abdominal discomfort. After finishing the repair, an intercostal tube was inserted, and the incision was closed in layers. An intercostal nerve block with xylocaine was used for analgesia. All patients were extubated directly in the operating room. Paracetamol and NSAID were used to control pain postoperatively.

\section{Statistical analysis}

Statistical analysis was performed using SPSS (SPSS version 25; IBM Corporation, Chicago, USA, August 2017). The results are expressed as mean \pm SD for patients' characteristics, the level of the eventrated diaphragm in $\mathrm{cm}$, and spirometry. A $P$ value of $<0.05$ was considered statistically significant.

\section{Results \\ Clinical data}

There were 40 symptomatic adults with UDE and underwent SDP, $30(75 \%)$ of them were males, their mean age, $45 \pm 14$ years. UDE was left-sided in 23 (57.5\%) patients. According to the etiology, 34 (85\%) patients were idiopathic, and $5(12.5 \%)$ patients were post-cardiac surgery and one (2.5\%) patient after cryoablation. Dyspnea (grades III and IV) was found in $37(92.5 \%)$ patients. Three $(7.5 \%)$ patients were suffering from deterioration of their sports activities. A markedly raised cupola was detected in all cases. Sixteen (40\%) patients underwent their SDP through the VATS procedure and 24 (60\%) via posterolateral thoracotomy. SDP was done successfully in all cases, and no intraoperative complications were reported. All cases were extubated on-table. The mean length of surgery was $48.8 \pm 19.7$ (range 30-70) min. The mean hospital stay was 5 days. The mean duration of chest tube drainage was 3 days. Postoperative complications were reported in $3(7.5 \%)$ cases, with no mortality. One patient suffered from pneumonia treated with antibiotics and oxygen. Two patients complained of chronic post-thoracotomy pain relieved by analgesics. No recurrence was detected throughout the follow-up period. There was a highly significant improvement in dyspnea at 1 week; grades I \& II in $33(82.5 \%)$ cases $(P<0.001)$, and at 6 months; grades I \& II in $35(87.5 \%)$ cases $(P<0.001)$ postoperatively, compared to preoperative values [Tables 1 and 2].

\section{Chest X-ray}

Preoperatively, CXR showed an elevated cupola on the affected side in all cases, and the main height of eventration was $10.1 \pm 2.8 \mathrm{~cm}$. The degree of eventration was $>8 \mathrm{~cm}$ in $6(15 \%), 8-5 \mathrm{~cm}$ in $30(75 \%)$, and $<5 \mathrm{~cm}$ in $4(10 \%)$. After SDP, CXR showed a highly significant decrease in the main height of eventration at 1 week $3.7 \pm 1.2 \mathrm{~cm} \quad(P<0.001)$, and 6 months $2.6 \pm 0.9 \mathrm{~cm}$ $(P<0.001)$, compared to preoperative values [Table 2].

\section{Diaphragm ultrasonography}

Preoperatively, DUS showed an elevated cupola on the affected side in all cases; the main height of eventration was $10.3 \pm 2.2 \mathrm{~cm}$, with no diaphragmatic movement in $10(25 \%)$ patients and a paradoxical movement in $30(75 \%)$ patients. The thickness of the eventrated side was $2.1 \pm 0.5 \mathrm{~mm}$, and the degree of the excursion was $15 \pm 6.2 \mathrm{~mm}$. After SDP, there was a highly significant decrease in the main height of eventration 
Table 1 Preoperative, operative, and postoperative data of the study cases

\begin{tabular}{ll}
\hline Variable & Results \\
\hline Age years (mean \pm SD) & $45 \pm 14$ \\
Gender: male/female & $30 / 10$ \\
Lateralization: left/right & $23 / 17$ \\
Etiology & \\
$\quad$ Idiopathic & $34(85 \%)$ \\
$\quad$ Postcardiac surgery & $5(12.5)$ \\
Cryoablation & $1(2.5)$ \\
Mean length of surgery was (min) & $48.8 \pm 19.7$ \\
& $($ range: \\
Mean hospital stay (day) & $30-70)$ \\
Mean duration of chest tube drainage) day ( & 5 \\
Postoperative complications & 3 \\
Pneumonia & $3(7.5 \%)$ \\
Chronic post-thoracotomy pain & $1(2.5)$ \\
Mortality recurrence & $2(5 \%)$ \\
& 0 \\
\hline
\end{tabular}

at 1 week $(3.1 \pm 1.1 \mathrm{~cm}, \quad P<0.001)$, and 6 months $(2.3 \pm 0.5 \mathrm{~cm}, P<0.001)$ compared to preoperative values. All cases (100\%) showed normal motility of the plicated cupola, and no paradoxical movement was detected. There was a highly significant increase in the diaphragm thickness at 1 week $(2.7 \pm 0.3 \mathrm{~mm}, P<0.001)$ and 6 months $(2.9 \pm 0.2 \mathrm{~mm}, P<0.001)$, compared to the preoperative value. The plicated cupola appeared doublelayered. There was a highly significant improvement in the degree of excursion at 1 week $(25 \pm 4.3 \mathrm{~mm}, P<0.001)$ and 6 months $(28 \pm 5.2 \mathrm{~mm}, P<0.001)$, compared to the preoperative value. No fluid collection or surrounding organ injuries were detected (Table 2).

\section{Respiratory function tests}

The mean preoperative FVC and FEV1 were $58.8 \pm 8 \%$ and $70.9 \pm 10.3 \%$, respectively. RFT showed a restricted value in $32(80 \%)$ cases and combined restricted and obstructed value in $8(20 \%)$ cases. After SDP, the mean FVC and FEV1 showed a highly significant improvement at 1 week $(66.7 \pm 6 \%, 78.2 \pm 9.8 \%, P<0.001)$ and 6 months (68.8 $\pm 5.7 \%, 80.4 \pm 10.3 \%, P<0.001)$, compared to the preoperative value (Table 2). Figures 1, 2, 3, and 4 showed sample cases of the study group population.

\section{Discussion}

In this study, we evaluated the outcome of SDP in forty symptomatic UDE adults at short-term follow-up. There was a significant improvement in dyspnea, RFT, and a decrease in the main height of eventration after plication. SDP was done successfully in all cases without intraoperative complications. All cases were extubated on-table. Postoperative complications were reported in three

Table 2 Comparison between the preoperative dyspnea, CXR, DUS, and RFT, and the postoperative follow-up at 1 week and 6 months

\begin{tabular}{|c|c|c|c|c|c|}
\hline \multirow[t]{2}{*}{ Variable } & \multirow[t]{2}{*}{ Preoperative (I) } & \multicolumn{2}{|c|}{ Postoperative } & \multirow[t]{2}{*}{$P$ values I \& II } & \multirow[t]{2}{*}{$P$ values I \& II } \\
\hline & & 1 week (II) & 6 months (III) & & \\
\hline \multicolumn{6}{|l|}{ Dyspnea } \\
\hline I & 0 & $4(10 \%)$ & $7(17.5 \%)$ & $<0.001$ & $<0.001$ \\
\hline$\|$ & $3(7.5 \%)$ & $29(72.5 \%)$ & $28(70 \%)$ & & \\
\hline III & $28(70 \%)$ & $6(15 \%)$ & $5(13.5 \%)$ & & \\
\hline IV & $9(22.5 \%)$ & $1(2.5 \%)$ & 0 & & \\
\hline CXR: Height of diaphragm (cm) & $10.1 \pm 2.8$ & $3.7 \pm 1.2$ & $2.6 \pm 0.9$ & $<0.001$ & $<0.001$ \\
\hline DUS & $10.3 \pm 2.2$ & $3.1 \pm 1.1$ & $2.3 \pm 0.5$ & $<0.001$ & $<0.001$ \\
\hline \multicolumn{6}{|l|}{ Height of diaphragm (cm) } \\
\hline Diaphragmatic thickness (mm) & $2.1 \pm 0.5$ & $2.7 \pm 0.3$ & $2.9 \pm 0.2$ & $<0.001$ & $<0.001$ \\
\hline \multicolumn{6}{|l|}{ Diaphragmatic movement } \\
\hline Normal motility & 0 & 40 & 40 & $<0.001$ & $<0.001$ \\
\hline No movement & 10 & 0 & 0 & & \\
\hline Paradoxical & 30 & 0 & 0 & & \\
\hline Degree of excursion in normal breath (mm) & $15 \pm 6.2$ & $25 \pm 4.3$ & $28 \pm 5.2$ & $<0.001$ & $<0.001$ \\
\hline Complications (effusion or organ injury) & & No & No & & \\
\hline \multicolumn{6}{|l|}{ RFT: } \\
\hline FVC (mean \pm SD \%) & $58.8 \pm 8$ & $66.7 \pm 6$ & $68.8 \pm 5.7$ & $<0.001$ & $<0.001$ \\
\hline FEV1 (mean \pm SD \%) & $70.9 \pm 10.3$ & $78.2 \pm 9.8$ & $80.4 \pm 10.3$ & 0.002 & $<0.001$ \\
\hline
\end{tabular}




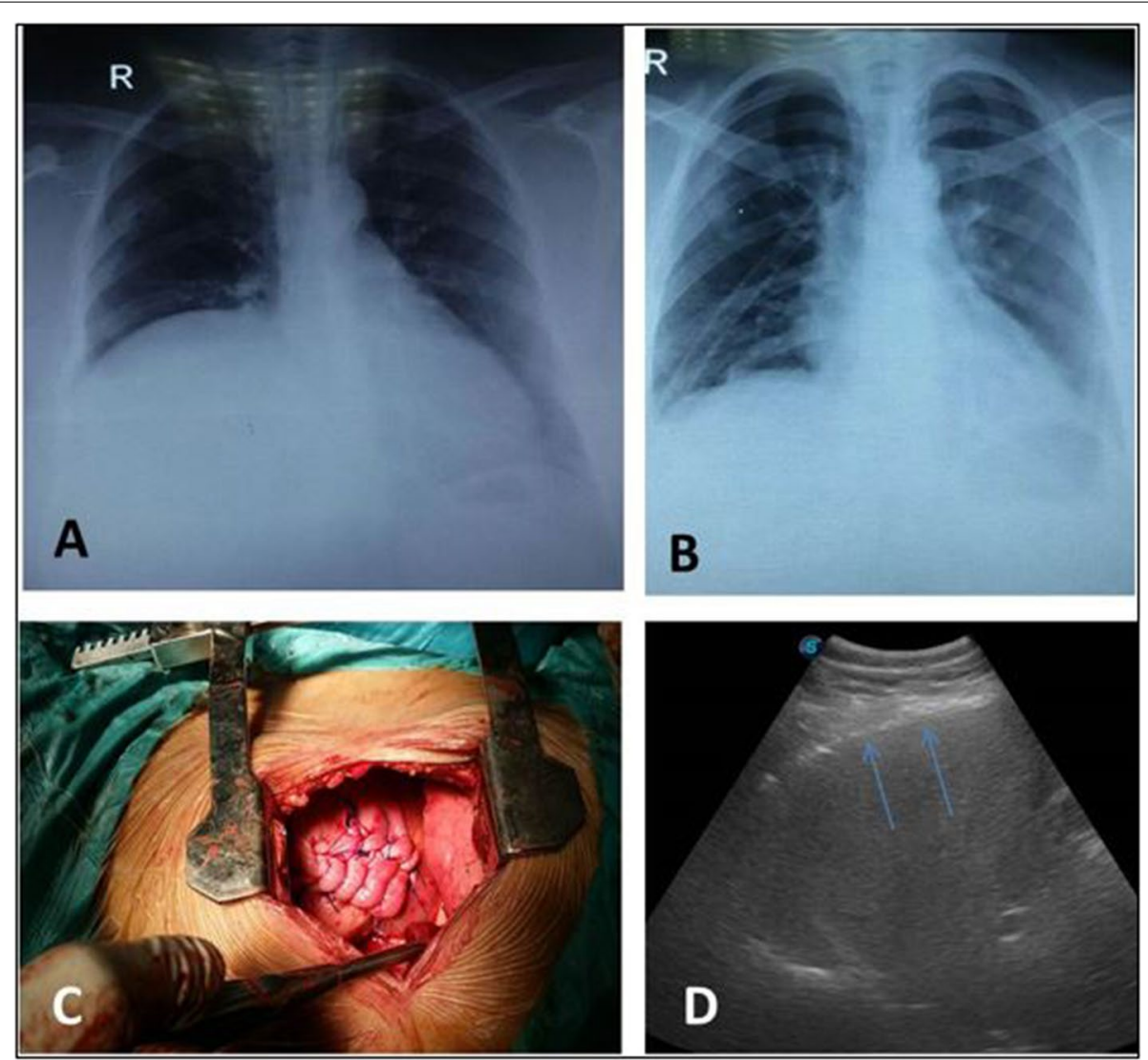

Fig. 1 Female patient 38 years old with right diaphragmatic paralysis: A Pre-operative CXR showing significant right diaphragmatic paralysis. B Post-operative CXR with an intercostal tube. C Intraoperative photograph after the end of plication. D Post-operative DUS image showing the right diaphragm (arrows)

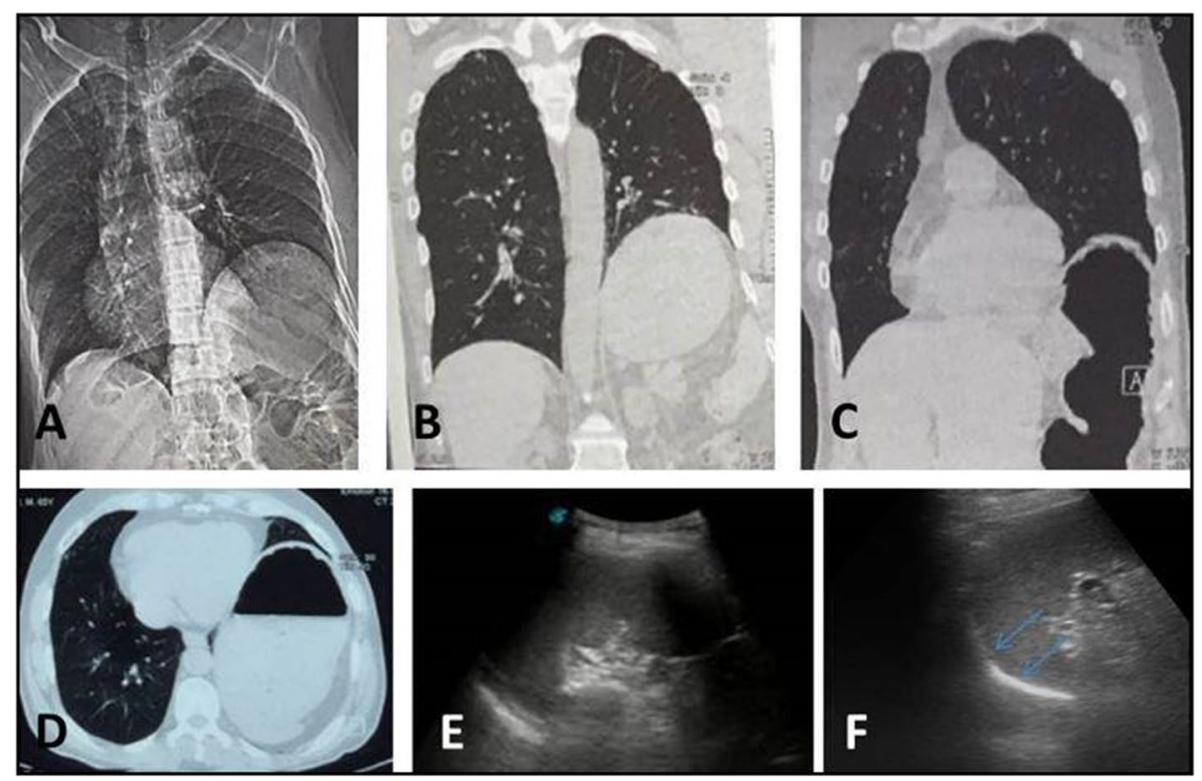

Fig. 2 Male patient 60 years old with left diaphragmatic paralysis: A Pre-operative CXR showing significant left diaphragmatic paralysis. B-D CT images showing the gastric contents at the site of the paralysis. E, F Post-operative DUS images showing the left diaphragm (arrows) 


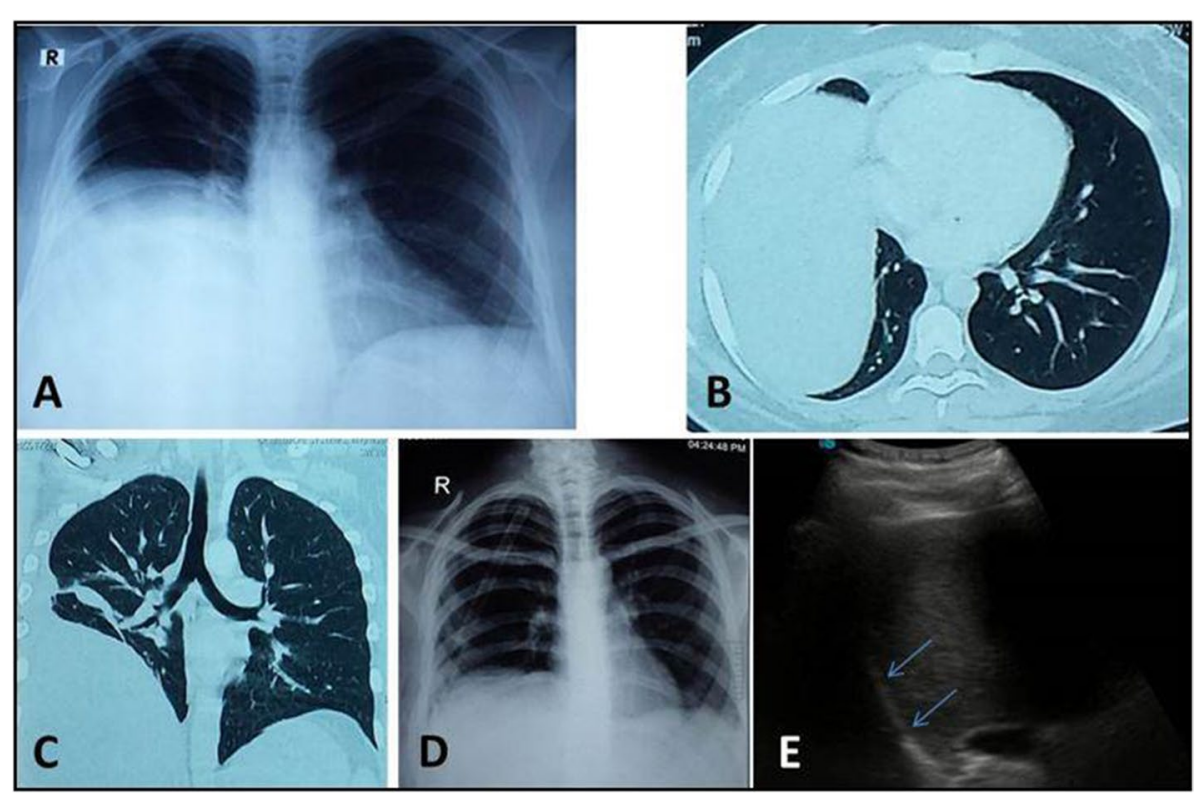

Fig. 3 Female patient 22 years old with right diaphragmatic paralysis: A Pre-operative CXR showing significant right diaphragmatic paralysis. B, C $\mathrm{CT}$ chest images showing the liver at the site of the paralysis. D Post-operative CXR with an intercostal tube. E Post-operative DUS image showing the right diaphragm (arrows)

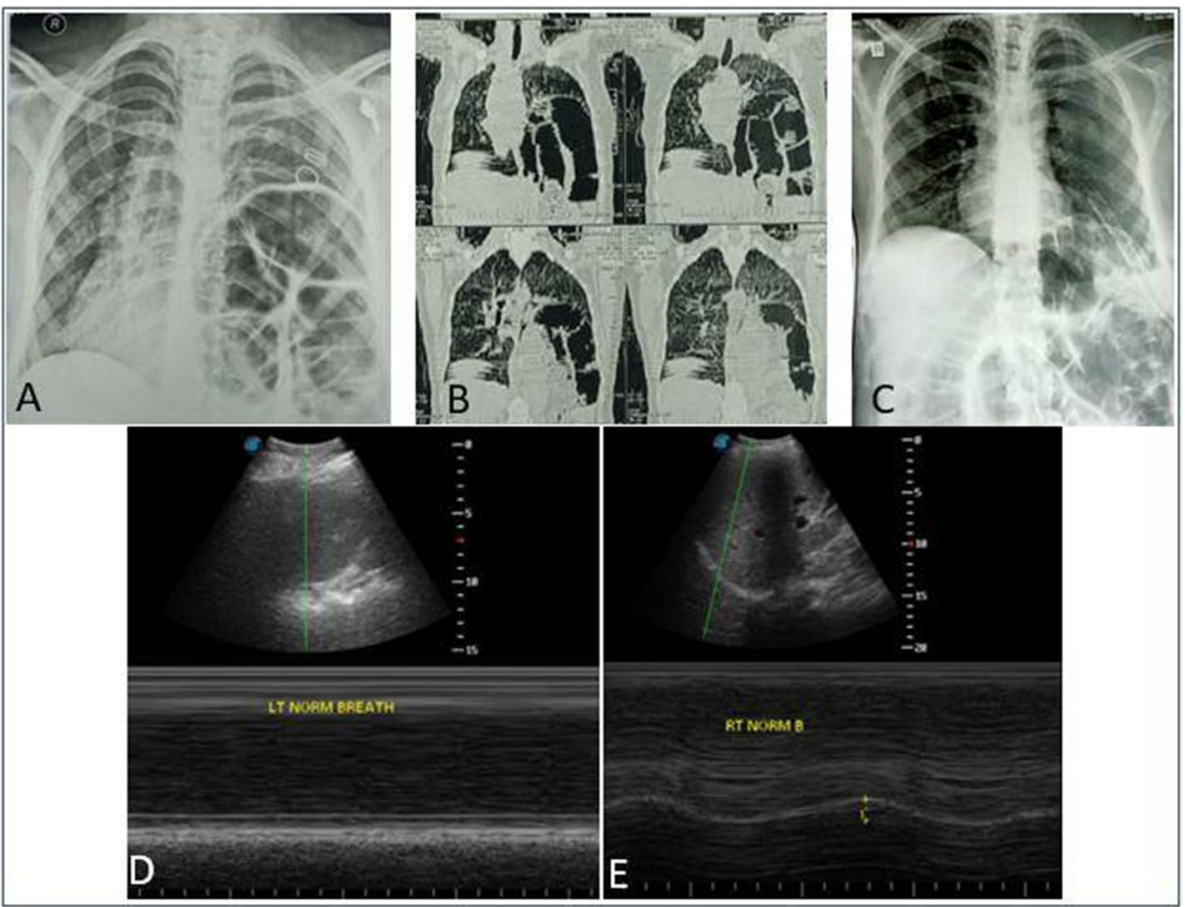

Fig. 4 Female patient 25 years old with left diaphragmatic paralysis: A Pre-operative CXR showing significant left diaphragmatic paralysis. B CT chest images showing the intestine at the site of the paralysis. C Post-operative CXR with an intercostal tube. D, E Pre-operative DUS image comparing left to right diaphragm 
cases, with no mortality. No recurrence was detected throughout the follow-up period.

Our results are supported with other reports that found that SDP resulted in a significant improvement in respiratory distress and RFT. Similarly, a series by Higgs et al. reported that SDP is a suitable and effective choice for the management of UDE patients over long-term followup. In our study, there was a marked improvement in the dyspnea score and patient satisfaction correlating with an improved FEV1 and FVC. There was one case who felt that his state had not been changed by plication although there was an initial improvement in spirometric values postoperatively. This one patient showed a deterioration of lung function later, which may have been confounded by his coexistent myasthenia gravis [18].

Freeman et al. reported a recovery in spirometry values in 41 case series at 6 months and over long-term follow-up [19]. Ribet found a 15\% increase in FEV1 and a 20\% increase in vital capacity following plication [20]. Also, Calvinho et al. described the long-term follow-up of twenty patients. Most of the patients had an important impairment of their daily activities preoperatively and all except three improved their physical status after the SDP [21].

We used to do a routine DUS to evaluate the diaphragmatic movement in both pre and postoperative periods. Preoperatively, DUS examination showed an elevated cupola on the affected side in all cases. There was no diaphragmatic movement in ten patients and a paradoxical movement in thirty patients. All patients showed an elevation of the diaphragm with a mean height of $10 \mathrm{~cm}$. After SDP, there was a highly significant decrease in the main height of eventration. All cases (100\%) showed either no or normal motility of the plicated cupola, but no paradoxical movement was detected. There was a highly significant increase in the diaphragm thickness. The plicated cupola appeared double-layered. There was a highly significant improvement in the degree of excursion. No fluid collection or surrounding organs injuries were detected.

DUS is a real-time dynamic examination. Moreover, it is a reliable, portable, and safe method in the examination of the diaphragm. It could illustrate the movement of the diaphragm, its thickness, and excursion. DUS was helpful in the diagnosis, which can be confirmed by elevation of the affected side, immobility, or paradoxical movement of the affected diaphragmatic cupola, and decreased thickness compared to the healthy side. Also, postoperative DUS examination is helpful for the assessment of the degree of correction of eventration and to assess the success of the operation by evaluating the integrity of the diaphragm as well as the surrounding structure to exclude complications as blood collection, effusion, or organ injury. In our opinion and following other reports, the DUS is the technique of choice for assessing diaphragmatic movement on suspicion of diaphragmatic malfunction [22].

\section{Study limitations}

Unfortunately, the rarity of diaphragmatic eventration precludes the possibility of performing randomized studies to assess accurate comparisons. This is a retrospective study, which has the potential for information bias. The completeness of the information cannot be assured. There was no standard format for the collection of data preoperatively and postoperatively. In this study, we did not focus on the surgical technique as the numbers are small for VATS plication to put into consideration the learning curve of such a new procedure. The follow-up data are scanty and were not processable; the follow-up was short (6months); therefore, there are no long-term results of sustainability. We, therefore, call for caution when interpreting the results of our study. Firm conclusions regarding the safety and efficacy of VATS diaphragmatic plication cannot be drawn from this study. The long-term outcomes of minimally invasive techniques need to be evaluated.

\section{Conclusions}

SDP is an effective and safe procedure that can be performed to treat symptomatic adults with UDE. DUS can be used as a simple bedside test for the initial evaluation of UDE cases and their postoperative follow-up.

\section{Abbreviations}

UDE: Unilateral diaphragmatic eventration; SDP: Surgical diaphragmatic plication; DUS: Diaphragm ultrasonography; RFT: Respiratory function tests; CXR: Chest X-ray; FEV1: Forced expiratory volume 1; FVC: Forced vital capacity.

\section{Acknowledgements}

To the patients who were included in the study and came back to our hospital at pre-determined regular visits for follow-up.

\section{Authors' contributions}

Mohamed Abdel-Bary and Alaa Rashad contributed substantially to the study design, data analysis and interpretation, and the writing of the manuscript. Hamed Elgendy contributed substantially to data editing and statistical analysis. Mohammed Zaki and Mahmoud Youssef Abdelhamid; wrote this article and interpreted the radiological data. Morris Beshay contributed substantially to the figures design and revision of the manuscript. Khaled Mohamed Abdelaal contributed substantially to data interpretation, and the writing of the manuscript. The authors have read and approved the final manuscript.

\section{Funding}

This research did not receive a grant from any funding agency in the public or commercial sectors.

Availability of data and materials

Not applicable. 


\section{Declarations}

Ethics approval and consent to participate

The study conforms to the ethical standards of the Helsinki Declaration, and approval was obtained from the institutional ethics committee of Qena Faculty of Medicine. ClinTrial.Gov:NCT04052295

\section{Consent for publication}

Not applicable.

\section{Competing interests}

The authors declare that they have no competing interests.

\section{Author details}

${ }^{1}$ Department of Cardiothoracic Surgery, Qena Faculty of Medicine, South Valley University, Safaga Road, Qena 83523, Egypt. ${ }^{2}$ Department of chest diseases, Qena faculty of medicine, South Valley University, Qena, Egypt. ${ }^{3}$ Anaesthesia Department, Faculty of Medicine, Assiut University, Assiut, Egypt. ${ }^{4}$ Department of Radiology, Sohag Faculty of Medicine, Sohag University, Sohag, Egypt. ${ }^{5}$ Department of Radiology, Sohag Faculty of Medicine, Sohag University, Sohag, Egypt. ${ }^{6}$ Department of General Thoracic Surgery, Protestant Hospital of Bethel Foundation, Teaching Hospital of the University of Westfalia, Muenster, Germany. ${ }^{7}$ Department of Cardiothoracic Surgery, Sohag Faculty of Medicine, Sohag University, Sohag, Egypt.

Received: 4 November 2021 Accepted: 17 December 2021

Published online: 15 January 2022

\section{References}

1. Mouroux J, Venissac N, Leo F, Alifano M, Guillot F (2005) Surgical treatment of diaphragmatic eventration using video-assisted thoracic surgery: a prospective study. Ann Thorac Surg 79(1):308-312

2. Gazala S, Hunt I, Bédard ELR (2012) Diaphragmatic plication offers functional improvement in dyspnoea and better pulmonary function with low morbidity. Interact Cardiovasc Thorac Surg 15(3):505-508

3. Elshafie G, Acosta J, Aliverti A et al (2016) Chest wall mechanics before and after diaphragm plication. J Cardiothorac Surg 11:25

4. Onders PR. Physiology of the diaphragm and surgical approaches to the paralyzed diaphragm. Shields' General Thoracic Surgery 8th ed Philadelphia: Wolters Kluwer. 2018:664-72

5. Gruber PJ (2017) Diaphragm plication: when and why to do it. J Thorac Cardiovasc Surg 154(5):1712-1713

6. Freeman RK, Wozniak TC, Fitzgerald EB (2006) Functional and physiologic results of video-assisted thoracoscopic diaphragm plication in adult patients with unilateral diaphragm paralysis. Ann Thorac Surg 81(5):1853-1857

7. Groth SS, Andrade RS (2010) Diaphragm plication for eventration or paralysis: a review of the literature. Ann Thorac Surg 89(6):S2146-S2S50

8. Versteegh MI, Braun J, Voigt PG, Bosman DB, Stolk J, Rabe KF et al (2007) Diaphragm plication in adult patients with diaphragm paralysis leads to long-term improvement of pulmonary function and level of dyspnea. Eur J cardio-Thor Surg 32(3):449-456

9. Demos DS, Berry MF, Backhus LM, Shrager JB (2017) Video-assisted thoracoscopic diaphragm plication using a running suture technique is durable and effective. J Thorac Cardiovasc Surg 153(5):1182-1188

10. Le Pimpec-Barthes F, Hernigou A, Mazzella A et al (2019) Dynamic magnetic resonance imaging in unilateral diaphragm eventration: knowledge improvement before and after plication. JThorac Dis 11(8):3467-3475 https://doi.org/10.21037/jtd.2019.07.79

11. Celik S, Celik M, Aydemir B, Tunckaya C, Okay T, Dogusoy I (2010) Long-term results of diaphragmatic plication in adults with unilateral diaphragm paralysis. J Cardiothorac Surg 5(1):1-7

12. Seok Jl, Kim KC, Rha HJ, Lee SR (2018) Sonographic evaluation of the diaphragm in patients with unilateral diaphragmatic paralysis. Ann Clinical Neurophysiology 20(2):93-96

13. Ueki J, De Bruin PF, Pride NB (1995) In vivo assessment of diaphragm contraction by ultrasound in normal subjects. Thorax. 50(11):1157-1161
14. Cappellini I, Picciafuochi F, Bartolucci M, Matteini S, Virgili G, Adembri C (2020) Evaluation of diaphragm thickening by diaphragm ultrasonography: a reproducibility and a repeatability study. J Ultrasound

15. Zambon M, Greco M, Bocchino S, Cabrini L, Beccaria PF, Zangrillo A (2017) Assessment of diaphragmatic dysfunction in the critically ill patient with ultrasound: a systematic review. Intensive Care Med 43(1):29-38

16. Sabri YY, Hussein SA, Baz AA, Aglan AA (2019) Ultrasonographic evaluation of the diaphragm, Egyptian. J Bronchology 13:690-698

17. Sferrazza Papa GF, Pellegrino GM, Di Marco F et al (2016) A review of the ultrasound assessment of diaphragmatic function in clinical practice. Respiration 91:403-411

18. Graham DR, Kaplan D, Evans CC, Hind CR, Donnelly RJ (1990) Diaphragmatic plication for unilateral diaphragmatic paralysis: a 10-year experience. Ann Thorac Surg 49(2):248-251 discussion 52

19. Freeman RK, Van Woerkom J, Vyverberg A, Ascioti AJ (2009) Long-term follow-up of the functional and physiologic results of diaphragm plication in adults with unilateral diaphragm paralysis. Ann Thorac Surg 88(4):1112-1117

20. Ribet M (1990) Diaphragmatic plication. Annals Thor Surg 50(5):855-856

21. Calvinho P, Bastos C, Bernardo JE, Eugénio L, Antunes MJ (2009) Diaphragmatic eventration: long-term follow-up and results of open-chest plicature. Eur J Cardiothoracic Surg 36(5):883-887

22. Farghaly S, Hasan AA (2017) Diaphragm ultrasound as a new method to predict extubation outcome in mechanically ventilated patients. Australian Crit Care 30(1):37-43

\section{Publisher's Note}

Springer Nature remains neutral with regard to jurisdictional claims in published maps and institutional affiliations.

\section{Submit your manuscript to a SpringerOpen ${ }^{\circ}$ journal and benefit from:}

- Convenient online submission

$\checkmark$ Rigorous peer review

- Open access: articles freely available online

- High visibility within the field

- Retaining the copyright to your article

Submit your next manuscript at $>$ springeropen.com 